\title{
O psicólogo no hospital geral: estilos e coletivos de pensamento
}

\author{
Fabia Monica Souza dos Santos ${ }^{1}$ \\ Universidade Estácio de Sá, Rio de Janeiro-RJ, Brasil \\ Ana Maria Jacó-Vilela \\ Universidade do Estado do Rio de Janeiro, Rio de Janeiro-RJ, Brasil
}

\begin{abstract}
Resumo: O artigo busca refletir sobre alguns embasamentos acerca das diferentes configurações do psicólogo que atua na área da saúde, em especial no hospital geral, com o objetivo de ampliar o conhecimento sobre o que constitui este ajustamento profissional. Como resultado, indicamos quatro coletivos de pensamento que julgamos serem os mais comuns: Psicologia Hospitalar, Psicologia Médica, Saúde Mental e Psicologia da Saúde. Apontamos algumas das especificidades desses coletivos, destacando a necessidade da realização de pesquisas em que os psicólogos atuantes em instituições hospitalares possam narrar suas histórias de inserção e delimitação da práxis profissional.
\end{abstract}

Palavras-chave: hospitais gerais, psicologia da saúde, história da psicologia.

\section{Psychologists in general hospitals: styles and collectives of thought}

\begin{abstract}
This article aims to reflect upon the different configurations of psychologists who work in the health field, specifically in a general hospital, with a view to improve knowledge on what constitutes this professional adjustment. As a result, we indicate four collectives of thought that we judge to be the most common: Hospital Psychology, Medical Psychology, Mental Health and Health Psychology. We point some of the peculiarities of these collectives, highlighting the need of further research in which psychologists working in hospitals can narrate their histories of insertion and delimitation of the professional practice.
\end{abstract}

Keywords: hospital general, health care psychology, history of psychology.

\section{El psicólogo en el hospital general: estilos y colectivos de pensamiento}

Resumen: Ese artículo reflexiona sobre algunos fundamentos de las diversas configuraciones del psicólogo que actúa en el área de la salud, especialmente en el Hospital General, con el objetivo de ampliar el conocimiento acerca de los elementos constituyentes de ese ajuste profesional. Como resultado de esta investigación, llegamos a cuatro colectivos de pensamiento que juzgamos ser los más comunes: Psicología del Hospital, Psicología Médica, Salud Mental y Psicología de la Salud. Señalamos algunas de las particularidades de estos colectivos, poniendo en relieve la necesidad de realizar investigaciones en las cuales los psicólogos que actúan en instituciones hospitalares puedan narrar sus historias de inserción y delimitación de la práctica profesional.

Palabras clave: hospitales generales, psicología de la salud, historia de la psicología.

Os relatos cotidianos de psicólogos inseridos na área da saúde no Brasil, aliados a alguns trabalhos descritos na literatura especializada (Fongaro \& Sebastiani, 1996; Pitta, 1999; Gioia-Martins \& Rocha Júnior, 2001; Angerami-Camon, 2002; Spink, 2003; Pereira, 2003; Straub, 2005), apontam uma progressiva incorporação destes profissionais nos mais diversos locus de atuação: hospitais especializados, Centros de Atenção Psicossocial (CAPS), postos de saúde, Programas de Saúde da Família, institutos e hospitais gerais e de emergência. Principalmente se tomarmos como referência a década de 1990, pois nela temos o início da ampliação exponencial nas vagas oferecidas tanto no segmento privado quanto no setor público.

Tradicionalmente, a idéia de "saúde" se confundia no campo de atuação do psicólogo com a atuação na clínica privada, que com o passar do tempo, sofreu redução e/ou modificações em suas possibilidades de atuação, dando lugar à nova perspectiva de inserção do psicólogo na saúde. Esta idéia atualmente compõe um cenário híbrido, no qual

1 Endereço para correspondência:

Prof. Dra. Fabia Monica Souza dos Santos. Universidade Estácio de Sá, campus R9 (Taquara/RJ). Rua André Rocha, 838. CEP 22.710-560. Rio de Janeiro-RJ, Brasil.E-mail: fabia@edu.estacio.br o aumento no número de profissionais da psicologia não foi acompanhado por um crescimento compatível na quantidade de pesquisas e nas diversas possibilidades de formação qualificada na área (Pereira, 2003).

Ao trazer estas considerações à tona, propomos no presente artigo discutir questões que perpassam a atuação dos psicólogos em hospitais gerais, abordando algumas das composições identitárias que julgamos mais presentes na atualidade. Evitamos, todavia, cair no risco da simplificação de que tais questões surgiram de forma natural, o que nos leva a enfocar também alguns aspectos históricos que possibilitam compreender as condições de expansão deste cenário, ao longo, principalmente, das três últimas décadas.

Nossas reflexões estão pautadas também na experiência cotidiana de uma das autoras como psicóloga da Secretaria de Estado de Saúde e Defesa Civil do Rio de Janeiro (SESDEC-RJ), e da pesquisa de doutorado realizada no Programa de Pós-graduação em Psicologia Social (PPGPS) da Universidade do Estado do Rio de Janeiro (UERJ) desde 2005, intitulada Histórias da Psicologia e dos seus atores no cenário da saúde: O hospital geral e seus nós. Como ponto de partida, destacamos que a incursão proposta em nossas investigações localiza-se, em seu mapa mais imediato, na área da Psicologia Social, a partir da qual propomos pensar a 
Psicologia e a Saúde como objetos negociados no cotidiano, nas relações que envolvem papéis, crenças, representações, em suas construções históricas sincrônicas e diacrônicas. Assim, objetivamos neste trabalho analisar algumas idéias que permitam situar nossa proposta tomando como questão principal a necessidade de decompor uma compreensão mais clara sobre a história e a prática da psicologia na saúde e no espaço complexo do hospital geral (HG).

Terreno dos mais híbridos, o HG comporta ao mesmo tempo a essência da multiprofissionalidade e a faceta do corporativismo, a multiplicidade do adoecimento e a singularidade de cada paciente, a Psicologia ancorada em diversas abordagens e a defesa por um campo unitário de atuação. Ao psicólogo que se aventura nesta seara torna-se necessário buscar subsídios para um estilo próprio de atuação.

Além do fato de se tratar de uma área recente no contexto brasileiro, principalmente se levarmos em consideração outras áreas mais clássicas da Psicologia, a interseção entre Psicologia e Saúde incorporou a dimensão social de diferentes formas ao longo das últimas décadas, atravessando três fases com características bastante peculiares, como nos aponta Spink (2003). Inicialmente, até pela proximidade temporal com o modelo de clínica privada, privilegiou-se a dimensão intra-individual, quando a psicogênese dos problemas de saúde e das teorias da personalidade permeou o arcabouço principal da Psicologia na área, fortemente influenciada pela corrente psicanalítica e pela psicossomática. A idéia de que a emoção "não domesticada" gera a doença predominava nessa primeira fase, que perdeu força a partir do momento em que se tornou possível reconhecer a multicausalidade do processo de adoecimento (Spink, 2003). Passam a ser consideradas, numa segunda fase, as "correlações entre eventos estressantes na vida do indivíduo e o aparecimento da doença, buscando nexos causais entre experiências de vida e o adoecer" (Spink, 2003, p. 45). Uma terceira fase, mais recente, vem apontar a doença como fenômeno psicossocial, construído historicamente e no qual a perspectiva do paciente passa a ser destacada e diretamente incorporada ao fazer dos profissionais de saúde. O que está em jogo não é mais explicitar a rede de causalidade da doença, para prevenir o seu surgimento, mas sim compreender a doença como um "indicador de ideologia de uma determinada sociedade" (Spink, 2003, p. 47). A doença deixa de ser uma experiência individual e a ótica privilegiada deixa de ser prioritariamente a do médico.

Tais fases não representam, de forma alguma, perspectivas estáticas claramente definidas. Mesmo com a incorporação de uma perspectiva psicossocial na interface entre Psicologia e Saúde, estas representações coexistem atualmente com algumas abordagens que continuam tratando as doenças em suas variáveis causais e individualmente originadas. Da mesma forma, embora a terceira fase descrita seja recente, é possível identificarmos perspectivas anteriores que já compreendiam a doença como um indicador ideológico de determinado grupo social, como é o caso da proposição de
Ludwik Fleck (Fleck, 1935/1979; Löwy, 1994; Pfuetzenreiter, 2002), como veremos logo adiante.

À luz das observações acima, consideramos que a reconstrução de algumas das diversas configurações que abrigam a Psicologia em sua interface com a área de Saúde, constitui o primeiro desafio a ser enfrentado para tratar o tema. As inúmeras abordagens do psicólogo que se aventura nesse cenário deixam transparecer um mosaico em que vários aspectos se diferenciam, ao mesmo tempo em que alguns deles se sobrepõem. São inúmeras perspectivas de atuação, delimitações, e diversos desafios.

Ao ingressar na área da Saúde, rapidamente o psicólogo é intimado a buscar uma alocação marcada pela escolha de uma abordagem específica para dar conta de sua prática profissional. Este fato o leva ao seguinte questionamento: que conjunto de técnicas e referencial teórico referenda a sua prática profissional nesse espaço multidimensionado? A tentativa de responder a essa pergunta pode incliná-lo a uma busca desordenada, nutrida pela rotina de uma instituição de saúde na qual a urgência das demandas exige uma ação imediata e muitas vezes solitária.

Pode ser difícil responder a qual destas delimitações se pertence, pois muitas vezes o psicólogo nem mesmo sabe quais são e como diferenciá-las. Trata-se de um aglomerado de idéias, que circunscrevem conjuntos de crenças, abordagens teóricas, estilos, estratégias de atuação e paradigmas, certa cultura que permeia cada um dos agrupamentos identitários em questão. Nesse cenário, destacamos quatro formatos para uma visita direcionada, como aqueles que, em nossa opinião, se apresentam como os mais impregnados no discurso cotidiano dos psicólogos que atuam em hospitais gerais.

Para realizar o percurso proposto, o presente artigo está organizado nas seguintes seções: a metodologia utilizada e nossa pesquisa; reflexões a partir dos conceitos de estilo e coletivo de pensamento de Fleck; alguns coletivos de Psicologia no hospital geral; e considerações finais.

\section{Método}

Trata-se de um estudo teórico, neste sentido, o percurso metodológico seguido voltou-se para composição de referências que pudessem contribuir para análise das contingências que levam psicólogos a construírem um determinado modelo de atuação na área da Saúde, mais especificamente no HG. Procedemos a um levantamento da literatura especializada referente tanto à história da inserção do psicólogo em hospitais gerais quanto aos diferentes tipos de atuação profissional que lá exercem. Além disso, investigamos a literatura de cunho sócio-profissiográfico que nos permitisse compreender as nuances deste trabalho e as perspectivas que auxiliam os psicólogos a construir suas estratégias de atuação nesse espaço.

Além do material bibliográfico, lançamos mão também de entrevistas com psicólogos de HG vinculados à SESDEC-RJ, 
quando conseguimos captar que aquilo que faziam poderia ser delimitado em diferentes denominações: Psicologia Hospitalar, Psicologia Médica, Saúde Mental e Psicologia da Saúde. Nossa empreitada foi justamente organizar o que cada um desses conjuntos representa. Para isso, usamos como instrumento os conceitos de Estilo de Pensamento e de Coletivo de Pensamento apresentados por Fleck em sua proposta epistemológica para a investigação em saúde.

\section{Reflexões a partir dos conceitos de Estilo e Coletivo de Pensamento de Fleck}

A proposta epistemológica de Ludwik Fleck (18961961) foi desenvolvida originalmente na década de 1930 e se referia, inicialmente, a uma nova abordagem sobre o desenvolvimento do conceito de sífilis. Sua proposição tornou-se referencial para a pesquisa na área de saúde, pois analisava a doença a partir de uma concepção dinâmica e histórica. Para Fleck, as enfermidades são entidades nosológicas em sua maioria fictícias, necessitando sempre de atualizações e modificações, o que instaura uma nova ordem de relacionamento com o "doente" e o fato científico que o envolve (Fleck, 1935/1979; Pfuetzenreiter, 2002). Como suas pesquisas estão voltadas basicamente para a produção de conhecimento no contexto da detecção da sífilis, suas conclusões apontam que a doença "não foi 'descoberta' apenas por um cientista, ou por um pequeno grupo deles, mas foi o produto de um esforço coletivo da comunidade de especialistas; além disso, foi moldada pelas múltiplas interações desta comunidade com outros grupos sociais" (Löwy, 1994, p. 236).

Com as noções de "coletivo de pensamento" e "estilo de pensamento", Fleck fornece contribuições preciosas para pensarmos sobre a forma como as informações passam a ser compartilhadas no cotidiano, criando significações e diferentes possibilidades de compreensão e modificação dos fatos sociais. É a partir destes pressupostos que realiza uma historiografia da pesquisa biomédica fundamentada na gênese e no desenvolvimento dos fatos científicos em um laboratório biomédico (Fleck, 1935/1979; Löwy, 1994; Pfuetzenreiter, 2002), fornecendo ainda subsídios para compreendermos o modo como indivíduos constroem sentido no dia-a-dia e, nosso interesse mais particular, como indivíduos escolhem e compartilham significados dentro de uma determinada marca profissional.

Nosso maior interesse na pesquisa realizada está relacionado às formas como psicólogos atuantes em hospitais gerais vivenciam os coletivos de pensamento que lhes são apresentados como possibilidades de atuação, como seus significados são compartilhados e as maneiras como cada profissional adere a essas marcas para compor seu próprio estilo de pensamento e sua singularidade de atuação. Propomos, dessa forma, uma apropriação da análise efetuada por Fleck para que possamos refletir, para além da construção de uma determinada categoria nosológica, sobre os constructos identitários que alocam os psicólogos no $\mathrm{HG}$ - por exemplo, aqueles da saúde mental, como os que trabalham com as doenças de risco psicossocial, ou os psicólogos da psicologia médica como aqueles que priorizam a relação médico paciente em sua atuação.

Em seus primeiros escritos, Fleck abordou o objeto da epistemologia como sendo a busca pela depuração de um "estilo de pensamento", ou seja, a disposição para o perceber orientado, a percepção dirigida para um foco e que leva à construção de um "coletivo de pensamento". Na verdade, não podemos falar de um único estilo de pensamento, mas sim de vários estilos que se encontram em constante revitalização. Essa pluralidade de estilos de pensamento leva a uma infinidade de coletivos de pensamento, cada um destes tentando forjar uma unidade. Estilo de Pensamento e Coletivo de Pensamento são, portanto, dois conceitos direcionados à mesclagem entre o caráter ao mesmo tempo individual e coletivo da construção de idéias pelos sujeitos em interação social.

Para Fleck, o estilo de pensamento cria a realidade a partir das negociações incessantes entre os atores, negociações que vão, progressivamente, materializando os fatos sociais. Tal realidade é dotada de organização e jogos inter-relacionais nos quais o coletivo de pensamento se consolida em um contexto em que idéias e significações são, até deter-minado ponto, compartilhadas. Dessa forma, tanto o coletivo de pensamento é nutrido pelos diferentes estilos de pensamento que o compõem quanto ao mesmo tempo possui a função de mediador desses estilos de pensamento, construindo-os.

Como afirma Pfuetzenreiter (2002, p. 151):

No conceito de coletivo de pensamento está impregnado o estado de conhecimento e meio cultural em que se encontra o sujeito cognoscente. (...). O conhecer é uma atividade condicionada socialmente, com ênfase na importância dos esforços coletivos na conquista do conhecimento científico. É muito difícil a observação de contribuições individuais. Assim, as idéias compartilhadas por um determinado grupo (coletivo de pensamento) formariam o estilo de pensamento. (...) O epistemólogo leva em consideração as diversas visões e interpretações de um mesmo fato por diferentes grupos de indivíduos, o que resulta em vários estilos de pensamento.

Nesta perspectiva, o pensamento se modifica constantemente em conformidade com os sistemas sociais de idéias que o circundam, sendo cada idéia pré-formada não a partir de uma origem individual, mas sim coletiva, na qual fato e conhecimento têm um caráter altamente temporário. Assim, o pensamento é uma rede intrincada de idéias estruturadas, rica em detalhes, o que garantiria a natureza homogênea das opiniões e uma regularidade histórica em seu desenvolvimento (Fleck, 1935/1979). Tais noções auxiliam na compreensão dos sistemas de pensamento que envolvem as vertentes da Psicologia em instituições de saúde, a enorme variedade de 
concepções que ora parecem se agrupar submissamente dentro dos títulos que as acolhem e ora parecem se desdobrar, perdendo sua identidade.

Em paralelo à perspectiva de Fleck, procuramos adotar a postura construcionista da qual fala Spink (2003, p. 25), ao buscar "fugir do enquadre intra ou interindividual, situando as pessoas na interseção de suas histórias pessoais e a história da sociedade em que vivem". As noções de coletivo e estilo de pensamento surgem nesse contexto para auxiliar a focalizar "as visões de mundo de pessoas pensadas como sujeitos ativos, produtores de conhecimento no afã de dar sentido ao mundo e que, nesse percurso, constroem efetivamente o mundo de artefatos e sociabilidade que chamamos de "realidade"' (Spink, 2003, p. 25).

Psicologia Hospitalar, Psicologia Médica, Saúde Mental e Psicologia da Saúde constituem algumas (em nosso olhar, as principais) unidades dentro do espaço do HG em que essas regras e orientações acabam sendo impostas, transformam-se em constructos representativos de diversos coletivos de pensamento, que se tornam as opções disponíveis aos que ingressam (Fleck, 1935/1979). No entanto, encaixar-se em um desses coletivos de pensamento pode ser uma tarefa um tanto quanto difícil, por dois motivos básicos e profundamente inter-relacionados. O primeiro deles é que esses agrupamentos são ainda cercados de uma significativa indefinição, carecendo de maior delimitação teórica e prática, dificultando assim uma escolha coerente. Além disso, os conteúdos inerentes à atuação do psicólogo em um HG circulam de forma flutuante entre os coletivos citados.

É dessa forma que nossa indagação caminha no sentido de tentar explicitar as idéias principais que constituem/ definem cada um desses coletivos. A motivação inicial está ligada à constatação de que, ao se nomear como psicólogo hospitalar, nada previamente determinado exclui este mesmo profissional de se utilizar de conhecimentos técnicos da Saúde Mental ou da Psicologia Médica, da mesma forma que os que se definem como psicólogos da saúde poderiam flutuar bem pelos outros coletivos. Mas na prática ocorre certo conhecimento, subliminar, que contra-indica uma aderência múltipla. Trata-se de uma espécie de imposição subjetiva pela qual o psicólogo se vê diante da obrigatoriedade de posicionamento, principalmente pelos demais colegas de profissão, levando a escolhas muitas vezes destituídas de coerência interna. Falamos aqui de uma pressão social no sentido da exigência para que o profissional se situe teórica e tecnicamente em um desses coletivos, posicionando-se e de certa forma situando seus pares em relação a seus embasamentos teóricos e suas estratégias de atuação na instituição hospitalar.

Tais posições parecem compor um campo ambíguo, no qual encontramos um conjunto de idéias e técnicas para o exercício da profissão ao psicólogo que se habilita a enveredar pela área da Saúde, ao mesmo tempo em que verificamos significativas dificuldades de nomeação da prática profissional e uma alocação que permite um exercício profissional menos conflituoso. Nesse sentido, tomamos emprestadas as palavras de Spink ao utilizar de dois argumentos aparentemente excludentes, o de que "a psicologia da saúde tem contornos claros e bem delimitados; e que a psicologia da saúde é um pântano de enfoques teóricos, com mais areia movediça do que terra firme" (Spink, 2003, p. 61). É a partir dessa zona de conflitos do exercício profissional que tecemos nossas inquietações, nesse sentido, explicitaremos a seguir coletivos de pensamentos em hospitais gerais.

\section{Alguns coletivos de psicologia no hospital geral}

Pensando a composição da psicologia em sua interface com a saúde, sugerimos a alocação do Rio de Janeiro como um tablado em que diversos modos de atuação estão ocorrendo simultaneamente, cada qual com a sua especificidade. Dentre esses esquetes, darmos prioridade à Psicologia da Saúde (PS), à Psicologia Hospitalar (PH), à Psicologia Médica (PM) e à Saúde Mental (SM) tem o objetivo não de apontar esses quatro coletivos de pensamento como os únicos que permeiam a atuação do psicólogo na área da saúde, ou como coletivos de pensamento rígidos e bem estruturados, mas sim defender que são, sem dúvida algumas, as mais comuns e bem estruturadas peças nas quais os psicólogos têm atuado ultimamente. A intenção desta metáfora não é a de apontar um caráter forjado na prática profissional do psicólogo que atua na área da saúde, mas sim a de aproximar o leitor a uma materialização destas reflexões de forma a torná-las mais concretas, principalmente para quem não circula pelos espaços e instituições de saúde em que se originam.

Seja na esfera do serviço público ou nas instituições privadas, a Psicologia ligada à área da Saúde, na realidade brasileira, ainda tem uma história significativamente recente. Há pouco mais de trinta anos começaram a se alocar de forma sistemática e oficial os primeiros psicólogos em instituições públicas de saúde no Brasil. O trabalho desenvolvido por eles engatinhava em discussões sobre interdisciplinaridade, análise institucional, psicossomática e, de uma maneira geral, sobre a própria questão da Saúde Mental.

A Psicologia Hospitalar, a Psicologia Médica, a Saúde Mental e a Psicologia da Saúde se apresentam como coletivos nos quais se enquadram especificidades e saberes dos diferentes tentáculos da nossa prática profissional, surgidas em momentos, contextos e situações absolutamente singulares. Nosso interesse é buscar compreender essas diferentes construções, como culturas que perpassam as maneiras como os psicólogos compreendem, elaboram e lidam com a rede dinâmica que envolve o palco da saúde em nosso país. Defendemos a hipótese de que se apresentar como psicólogo hospitalar ou como profissional de saúde mental, por exemplo, delimita não apenas um conjunto particular de referências teóricas e formas de atuação, mas fornece visibilidades muito específicas, permitindo uma determinada forma de circulação dentro do hospital e da comunidade de psicólogos e demais profissionais de saúde. 
Nossa investigação levou-nos a considerar, como um dos pontos principais para nossas reflexões sobre o tema, que cada profissional constrói paulatinamente o seu arcabouço teórico-prático a partir de um conjunto de saberes e fazeres marcados por sua história pessoal, incluindo a formação profissional. As escolhas de abordagem são formadas por um estilo pessoal, identificações com outros profissionais da área e processos de elaboração teórica. Assim, a formação obtida precisa se nutrir do acordo/confronto com a realidade de ação profissional para se estabelecer. Dessa forma, vamos procedendo a escolhas que nos levam a revalidar ou questionar nosso acervo conceitual para a área, fazendo com que, ao final, possamos dizer que escolhemos uma determinada linha ou abordagem.

Considerando esse processo, partimos do pressuposto de que cada um dos coletivos destacados aqui indica um conjunto de idéias, representações, preceitos teóricos, estilos de abordagem, técnicas e fundamentos que o delineiam formando uma especificidade. Esta, no entanto, apresenta uma enorme fluidez, que muitas vezes dissipa e mistura essas diferentes abordagens. Trata-se de um conjunto de negociações e renegociações que oscila entre o estilo de pensamento e o coletivo de pensamento dos quais Fleck trata. Em nosso caso, destacamos o estilo de pensamento como uma construção subjetiva que cada um cria a partir de sua apropriação dos conteúdos compartilhados em um plano coletivo. Ao recontar sua própria história de construção profissional e inserção em uma unidade hospitalar, cada psicólogo não apenas expõe elementos desses coletivos e estilos de pensamento, mas os recompõem.

$\mathrm{Na}$ análise desse panorama, um importante caminho, a nosso ver, é a historicização dessas especificidades. Assim, um marco histórico fundamental no resgate da atuação da Psicologia no âmbito da Saúde é o trabalho realizado pela psicóloga Matilde Neder a partir do início da década de 1950, no Hospital de Clínicas de São Paulo, em um registro que antecede à própria constituição da Psicologia enquanto profissão regulamentada. Trata-se da emergência da Psicologia Hospitalar no Brasil, que apresenta como suporte inicial a construção do trabalho psicológico por ela desenvolvido, durante algum tempo de forma solitária, na Clínica Ortopédica e Traumatológica do Hospital de Clínicas. Hoje, com pouco mais de 80 anos de idade, Matilde Neder ainda é uma figura ativa no cenário da Psicologia Hospitalar brasileira (Angerami-Camon, 2004).

Matilde Neder fundou uma maneira de fazer psicologia que visava articular os conhecimentos da Psicanálise e da Psicologia Analítica de Jung com uma abordagem breve, conciliando ainda a arte terapia e a terapia ocupacional. Surge intimamente vinculada à prática específica do psicólogo no hospital, abordando prioritariamente o paciente, a partir da compreensão dos processos de somatização e do contexto pessoal de adoecimento, com trabalhos realizados em diferentes setores dentro da unidade de saúde, cada um com sua especificidade.
O fato é que os primeiros psicólogos hospitalares no Brasil, já na década de 1950, na experiência de São Paulo, realizavam um trabalho de atendimento sistemático, tendo como uma das suas estratégias principais de atuação a preparação psicológica de pacientes para cirurgia, procedimento que só começa a ser melhor delimitado como estratégia de atuação a partir da década de 1980 (Doca \& Costa Júnior, 2007). As ações adotadas ainda de forma "intuitiva" no início da Psicologia em hospitais gerais vão sendo progressivamente constituídas como ferramentas técnicas, mas não podemos desconsiderar que muitas delas surgem em momentos históricos bem anteriores.

Além de Neder, historicamente outros nomes vão compondo a chamada Psicologia Hospitalar, mas a literatura específica mostra que se mantém a predominância do referencial teórico psicanalítico e da abordagem psicossomática. No entanto, podemos também encontrar uma vertente que realiza a Psicologia Hospitalar a partir da filosofia existencial-humanista, como citado por Angerami-Camon (2002). Seu pioneirismo resulta em um longo trabalho de delimitação, discussão e ensino que levou, em seus desdobramentos, a uma vertente que alia este ramo da Psicologia diretamente à abordagem da psicossomática.

Paralelamente outro coletivo foi se constituindo, denominado Psicologia Médica, com um trabalho assentado em bases diferentes das apontadas pela Psicologia Hospitalar, em um viés que a situa como área de conhecimento profundamente ligada ao saber médico, na medida em que se circunscreve justamente a partir de uma generalidade que não a torna especificidade do psicólogo. A Psicologia Médica se apresenta como uma disciplina interligada às diferentes especialidades que circulam pelos serviços de saúde, tendo como objeto principal a relação médico paciente, ou de forma mais genérica, a relação profissional de saúde paciente, em seus desdobramentos patogênicos ou terapêuticos, em uma abordagem primordialmente psicanalítica.

Como dado histórico, é pertinente citar que o primeiro curso de Pós-graduação em Psicologia Médica no Brasil foi criado em 1983, no Instituto de Pós-Graduação Médica Carlos Chagas (RJ), com uma filosofia de atuação que vem sendo desenvolvida no Centro de Medicina Psicossomática e Psicologia Médica do Hospital Geral da Santa Casa de Misericórdia do Rio de Janeiro. Dois nomes que se destacam nessa história inicial são Abram J. Eksterman, atualmente diretor do Centro de Medicina Psicossomática e Psicologia Médica do Hospital Geral da Santa Casa de Misericóridia do Rio de Janeiro, e Danilo Perestrello, fundador do referido centro, em uma forte vinculação com a Psicanálise.

A Psicologia Médica assenta-se na proposição do caráter dinâmico dos processos de adoecimento e de promoção de saúde, considerando fundamentais os processos psicossomáticos, porém privilegiando, nesta compreensão, as formas como o paciente se vincula e interage com os profissionais de saúde, bem como os processos de transferência envolvidos nessas relações. A interconsulta é apontada como 
instrumento primordial de atuação, pois se entende que a inter-relação é a possibilitadora de uma visão psicodinâmica sobre o processo de promoção de saúde.

A Psicologia Médica leva em consideração a interação entre corpo e mente, ou seja, considera os fatores psicológicos que afetam a condição médica, o que caracteriza sua visão psicossomática. Já na abordagem da Psicologia Hospitalar, a visão psicossomática surge atrelada à situação de diagnóstico de patologias como câncer, Aids, ou situações como a internação em unidades intensivas, amputações e intercorrências diretamente vinculadas ao processo de adoecimento, como elemento adjacente no referencial teórico da Psicologia Médica.

$\mathrm{Na}$ literatura especializada, os primeiros registros de psicólogos inseridos em instituições de saúde referem um trabalho que integrava o saber psicológico à educação médica (Gioia-Martins \& Rocha Júnior, 2001). Tal prática, no entanto, não ocorria nem de forma sistematizada nem sequencial, já que o próprio saber psicológico ainda se encontrava em busca de reconhecimento da sua especificidade.

Outro coletivo de destaque na formação e atuação dos psicólogos da área da Saúde é a Saúde Mental (SM). Nesse contexto, o marco fundamental é o movimento da Reforma Psiquiátrica, que implementou novos olhares e práticas em relação ao paciente com transtorno mental grave, redefinindo a própria definição de Saúde Mental: há um rompimento com a noção de doença mental e com a própria Psiquiatria, surgindo a noção de risco psicossocial. Utilizamos aqui a referência ao risco psicossocial como um conjunto de situações em que o indivíduo se encontra potencialmente exposto às exigências de sua existência que podem levá-lo a desencadear reações e respostas indesejadas e prejudiciais a si mesmo ou a terceiros. Diz respeito às ameaças que o meio externo $\mathrm{e}$ interno trazem ao sujeito, quando o indivíduo se encontra mais suscetível a apresentar respostas/reações insalubres, patológicas ou desadaptadas. Algumas das situações de risco psicossocial são os acidentes e violências (dados como epidemiologicamente relevantes e como principal atuação dos hospitais de emergência), envenenamentos (especificamente, as tentativas de suicídio), quadros psiquiátricos (inserindo-se aqui o alcoolismo e a drogadição), reações psíquicas à hospitalização (depressão, quadros de ansiedade, dentre outras), e também a atuação junto à gravidez de alto risco e à gravidez em adolescentes, situações que promovem quadros que propiciam e justificam uma atuação da Saúde Mental (Impagliazzo e cols., 2003). O mote principal trazido a partir da década de 1980 é a diminuição de leitos hospitalares até a progressiva desativação das unidades manicomiais, criando formas alternativas de atendimento à clientela dos chamados "doentes mentais". A preferência passa a ser a do modelo de atendimento que enfatiza a reintegração do paciente psiquiátrico à esfera social, o que leva à criação de uma série de suportes até então inexistentes: os modelos de atenção diária (hospitais-dia, CAPS), os modelos de assistência domiciliar, o atendimento nos hospitais gerais e a necessidade de criação de suporte nessas unidades, entre outros (Brasil, 2002).
A Saúde Mental se compõe como coletivo no qual circulam os mais diferentes saberes, de todos mencionados, é ela quem traz, de forma mais nítida, uma proposição políticoideológica aliada a uma diversidade de abordagens teóricopráticas. A maior parte das vertentes que compõem este coletivo tem sua origem nas militâncias que visavam caracterizar o doente mental como sujeito de valores e direitos, e não como doente estigmatizado.

Uma das discussões mais recentes na área diz respeito à viabilidade ou não de se criarem leitos psiquiátricos em unidades gerais de saúde (hospitais gerais), o que tem provocado intenso embate entre os profissionais da área. O debate acalorado vai ganhando cada vez mais espaço em um contexto no qual tem se tornado fundamental a expansão, concreta, do coletivo de Saúde Mental. Na atualidade, por exemplo, levando-se em consideração o contexto dos hospitais públicos municipais e estaduais no Rio de Janeiro, os Serviços de Psicologia têm sido progressivamente substituídos por equipes de Saúde Mental, multiprofissionais, compostas na sua grande maioria por psicólogos, psiquiatras e terapeutas ocupacionais.

Podemos, dessa forma, entender a Saúde Mental como uma área de articulação política e social compondo estilos de atuação profissional diversificados, nos quais a especificidade da atuação do psicólogo parece contrastar com as tentativas de constituir o campo como essencialmente multifacetado. Dessa forma, surge como disciplina aglutinadora do trabalho com demandas específicas, trazendo à tona a necessidade de reorganização e ampliação da noção de atenção psicossocial. $\mathrm{Na}$ atualidade, portanto, o foco tem caminhado no sentido da ampliação das demandas que dizem respeito à atuação em Saúde Mental, mas ainda permanece superficial a discussão acerca das competências específicas de cada um dos diferentes agentes dentro desse vasto coletivo de pensamento.

A Psicologia da Saúde (PS), nova disciplina específica dentro do saber psicológico contemporâneo, assim como todas as outras subdisciplinas psicológicas, surge após certa consolidação de seu campo de atuação, que passa a ser definido e delimitado como campo de conhecimento após aquele ganhar status e corporeidade na prática profissional de quem o compõe. Dessa forma, se a Psicologia inserida em instituições de saúde, no contexto brasileiro, começou a surgir como prática profissional de forma mais sistematizada e reconhecida na década de 1970, passou a ter status dentro da comunidade acadêmica e científica principalmente a partir da década de 1990. Neste ponto cabe a lembrança de que, no Brasil, a regulamentação do exercício da profissão de psicólogo ocorreu em agosto de 1962, e no seu início, o trabalho encontrava-se basicamente voltado para a área da clínica privada e para a interface com as áreas educacional e industrial. Historicamente permanece com demasiada força durante longo tempo a subdivisão que consagrou a "área clínica", a "área organizacional" e a "área escolar" como os três grandes carros-chefe da Psicologia (Yamamoto, 1990).

Como destaca Spink, "a psicologia da saúde emerge como uma colcha de retalhos de teorias que mal conversam 
entre si” (Spink, 2003, p. 27). Nessa múltipla composição, uma das primeiras referências à terminologia Psicologia da Saúde dentro da literatura psicológica pode ser encontrada em Abraham Maslow (s/d), que a apresenta a partir da proposta de uma nova concepção de doença e de saúde. Maslow demarca sua argumentação teórica baseado na perspectiva humanista, para a qual todo ser humano (em sua natureza) é bom ou neutro, composto por um núcleo essencial que o delimita. Dessa forma, uma das características da Psicologia da Saúde seria compreender o ser humano como sujeito de potencialidades intrínsecas que devem ser desenvolvidas, sendo a doença a negação ou supressão do desenvolvimento dessas potencialidades. A perspectiva de Maslow é uma tentativa de ruptura com a lógica de pensamento dominante em uma época em que os objetivos de adaptação e ajustamento do indivíduo eram predominantes na Psicologia. Mantém, contudo, o foco de atenção localizado no indivíduo, na forma característica da Psicologia da época. E de qualquer maneira, mesmo podendo ser utilizada como disparador de análise, a definição proposta por Maslow não se apresenta como uma abordagem preocupada em instrumentalizar a prática psicológica dentro das instituições de saúde. Antes de mais nada, compreende um conjunto de reflexões filosóficas que parecem diretamente relacionadas à interface entre subjetividade e saúde, longe da proposta pragmática defendida pela Psicologia da Saúde contemporânea.

$\mathrm{Na}$ atualidade, temos observado diferenciadas abordagens agrupadas sob esta mesma noção, com alguns autores delimitando a Psicologia da Saúde como um saber de articulação entre o indivíduo e a sociedade. Como nos apontam Gioia-Martins e Rocha Júnior (2001, p. 35, grifos nossos),

a saída dos psicólogos da clínica privada para uma preocupação maior com o contexto social traz um aumento de interesse na área de saúde, ampliandose o espaço público e as demandas do contexto institucional. A Psicologia da Saúde surge, então, da necessidade de promover a saúde e de pensar o processo saúde-doença como um fenômeno social. (...) Enfatiza-se a necessidade de conhecer a instituição, a realidade da saúde pública no Brasil, favorecendo uma visão crítica da psicologia em relação ao adoecer, à hospitalização e às relações sócio-culturais (...). A capacitação dos futuros profissionais deve enfatizar a especificidade de ação, possibilitar o desenvolvimento de reflexão crítica acerca do papel do psicólogo, de sua inserção e identidade profissional, numa visão biopsicossocial.

Trata-se da compreensão de que cada época e contexto cultural produzem determinadas formas de adoecimento, e que a Psicologia da Saúde estaria então vinculada a essas mudanças sociais. O modelo de profissional de Psicologia se transforma a partir das necessidades da sociedade (Gioia-Martins \& Rocha Júnior, 2001), fazendo com que possamos definir a Psicologia da Saúde como um conjunto de contribuições educacionais, científicas e profissionais específicas voltadas para a promoção da saúde, a prevenção e o tratamento das doenças, bem como o aperfeiçoamento do sistema de políticas de saúde (Matarazzo, 1980).

Podemos encontrar também definições da Psicologia da Saúde que seguem o modelo biopsicossocial como parâmetro básico, buscando transmitir as maneiras como os componentes deste modelo interagem de forma dinâmica para influenciar o bem-estar da pessoa como um todo, em uma visão cognitivo-comportamental na qual uma das prerrogativas principais é a mudança de comportamento (Straub, 2005). Do mesmo modo que encontramos concepções que ressaltam o caráter de articulação entre a ampliação do espaço público e as demandas do contexto social, nos deparamos com delimitações que estão intimamente vinculadas a fatores comportamentais ligados ao adoecimento físico e psíquico. Encontramos tais definições principalmente nos recentes manuais gerais de Psicologia e, neste referencial, a Psicologia da Saúde pode ser entendida como "a contribuição da psicologia à medicina comportamental" (Myers, 1999, p. 362), partindo de perguntas como estas: "Como nossas emoções e personalidade influenciam o risco da doença? Como as pessoas concluem que estão doentes, e quando procuram tratamento? Que atitudes e comportamentos ajudam a prevenir a doença e a promover a saúde e o bem-estar?" (Myers, 1999, p. 362).

Nessa perspectiva, o foco parece incidir diretamente sobre o indivíduo e sua doença, embora não exclua um olhar social. Além de apresentar uma perspectiva individualizada, define a especificidade da Psicologia da Saúde por sua vinculação com as doenças que se apresentam a partir dos estilos de vida adotados pelos indivíduos. Dessa forma, "os psicólogos da saúde estudam como estilo de vida e atividades físicas, reações emocionais, maneiras de interpretar eventos e características da personalidade influenciam a saúde física das pessoas" (Huffman, Vernoy, \& Vernoy, 2003, p. 455).

Como aponta Spink (2003), mudanças recentes na forma do psicólogo circular na área da saúde vêm gerando transformações qualitativas na prática, o que faz a Psicologia da Saúde se destacar a partir de uma estratégia diferencial em relação aos outros coletivos. Ao investigar o rol de definições para esta área, encontramos, pois, significados variados, que parecem simbolizar uma infinidade de práticas e concepções que perpassam também diferentes pontos de vista sobre subjetividade, doença, saúde, cultura e sociedade.

Num primeiro momento, acreditamos que o coletivo Psicologia da Saúde, pela sua contemporaneidade, significaria uma tentativa de constituir um saber parcialmente livre dos ranços e desgastes acumulados nas outras abordagens principais aqui citadas e que compõem a prática psicológica no espaço da saúde. Um olhar mais apurado, no entanto, tem revelado que ela também, ao lado dos outros coletivos, vem carregada por estilos de pensamento herméticos, que vão definindo distintos olhares, práticas e militâncias. 
Nesse sentido, a Psicologia da Saúde nos parece um coletivo de pensamento tão diversificado quanto reutilizado, já que em diversos momentos parece aproveitar na sua caracterização definições que toma das outras disciplinas afins. Mas é exatamente esta junção que a caracteriza, demonstrando em alguns momentos já estar estruturada e bem circunscrita enquanto disciplina psicológica, e em outras ocasiões, justamente pela pluralidade de definições e focos, demonstrar ser composta de protoidéias. Esta noção, de protoidéias ou pré-idéias, diz respeito às idéias iniciais vinculadas aos fatos científicos ainda mal delineadas e muitas vezes obscuras (Fleck, 1935/1979). Não se tratam de idéias incorretas, mas sim ainda imprecisas, "havendo uma tendência à persistência de ideias que já estão infiltradas dentro de um estilo de pensamento" (Pfuetzenreiter, 2002, p. 151).

Em síntese, a Psicologia da Saúde pode permitir a constituição de novos coletivos e estilos de pensamento tanto por ser composta por diferentes referenciais de outras disciplinas como por parecer buscar a delimitação de seu referencial teórico e prático, ainda difuso. O desenvolvimento de um campo quase sempre gera a pregnância a um estilo, já que "quanto mais desenvolvido é um campo do conhecimento, menores divergências de opinião irão ocorrer. O conhecimento vai se tornando uma estrutura rígida, com muitos pontos de confluência, deixando, portanto, pouco espaço para o desenvolvimento de outras formas de pensamento" (Pfuetzenreiter, 2002, p. 153).

Se um indivíduo circula por diversos coletivos de pensamento com uma movimentação intercoletiva e intracoletiva de idéias, assim também ocorre com um sistema de idéias mais ou menos estruturado, como é o caso de uma disciplina do campo do conhecimento. Nesse sentido, as contribuições de Fleck oferecem um importante subsídio no sentido de fundamentar a análise aqui apresentada, dos vários estilos de pensamento que compõem os diferentes extratos da Psicologia inserida em instituições de saúde e, em nosso caso, especificamente, em hospitais gerais de grande porte.

\section{Considerações finais}

Assumimos uma perspectiva que considera a Psicologia na área da Saúde como um grande guarda-chuva, sob o qual se agrupam não apenas práticas diversas, mas perspectivas às vezes complementares e às vezes antagônicas. Trata-se basicamente de um campo disciplinar marcado pela indefinição do objeto psicológico a ser delimitado e articulado com outros saberes, um conhecimento em construção e expansão. Se em determinadas épocas a atuação do psicólogo esteve prioritariamente calcada nas perspectivas psicanalíticas e psicossomáticas, e em outros a prioridade de abordagem dizia respeito à clínica exercida em instituições hospitalares, atualmente a amplitude das temáticas que envolvem o saber psi tornam difíceis todas as tentativas de delimitação.

Nosso olhar à temática do lugar do psicólogo nos hospitais gerais nos levou a destacar estes quatro coletivos de pensamento como registros impregnados na formação e atuação dos psicólogos nestas instituições. Ao mesmo tempo, ao elencar estes quatro coletivos, ressaltamos a fragilidade de seus limites, indicando uma urgente necessidade de entrecruzamento entre suas delimitações.

Escrever sobre uma História da Psicologia da Saúde levando em consideração lugares e tempos específicos não significa escrever ingenuamente, sabemos que ao delinear um objeto e submetê-lo à avaliação da comunidade científica, tornamo-lo um objeto de análise válido e valorizado. Não é o objeto em questão que se apresenta como válido, mas nós, da comunidade científica, que fornecemos à temática o status de objeto de pesquisa, enfatizando-o em todos os seus relevos, e com várias intenções embutidas. A história, nesse sentido, não apenas demarca práticas passadas, mas serve também como ancoragem para que novas práticas sejam compreendidas e desenhadas. O tempo muda as maneiras de narrar e dar significado à realidade.

A Psicologia se apresenta não apenas como uma ciência em permanente construção e reconfiguração, mas também como uma disciplina híbrida, originada de saberes com os mais diversos graus de contemporaneidade. Nessa configuração, a Psicologia Social pode ser considerada uma das áreas autenticamente fundamentadoras desta Psicologia, uma das grandes responsáveis pelo surgimento de tantas outras subdisciplinas psicológicas como, por exemplo, a Psicologia da Saúde, área que tem provocado inúmeras reflexões e discussões acerca de um cenário ainda recente na Psicologia brasileira. Ser psicólogo da saúde, antes de mais nada, significa ser psicólogo e ocupar um lugar de atuação marcado basicamente pela diversidade - de histórias, temáticas, práticas, concepções, abordagens e instituições em que essas práticas ocorrem. Parece-nos, pois, bastante pertinente analisar as configurações que têm marcado sua delimitação.

Além disso, adotar a lente da Psicologia Social da saúde para pensar nesse tema é mais uma razão para refletir sobre as demandas construídas na interface entre especialistas e comunidade usuária. Bem sabemos que o presente estudo assume uma perspectiva corporativista na medida em que destaca um conjunto de idéias voltado para a construção da carreira de psicólogo na área da saúde, mas podemos vislumbrar a idéia de que a qualidade da atenção e do atendimento prestados ao paciente está diretamente relacionada à forma como cada profissional constrói seu estilo de pensamento a partir dos coletivos compartilhados com seus pares. De forma complementar, nossas pesquisas apontaram a imensa importância de refletirmos também sobre a autopercepção dos psicólogos acerca de suas funções profissionais.

Pensar os lugares do psicólogo no hospital geral hoje em dia só é possível a partir do momento em que entendemos a constituição dos saberes vinculados à Psicologia e sua concretização material, nas instituições concretas. Em outras palavras, precisamos buscar dados que nos falem sobre como os psicólogos e suas histórias invadiram os hospitais e implementaram suas ações e concepções nesses lugares reais, 
marcados por lembranças pessoais, registros profissionais, interfaces políticas, desafios e sobressaltos, que acontecem em cada hospital de forma diferente.

Não há na Psicologia uma coesão de idéias e práticas que gere uma perspectiva de ação na área da Saúde de forma coerente, o que por um lado evita seu fortalecimento, mas por outro, gera a possibilidade de uma variedade enorme de atuações e estilos. A própria diversidade de perspectivas e de nomenclaturas para descrever a prática profissional do psicólogo na área da Saúde gera um terreno excessivamente híbrido, sendo, portanto, um dos maiores celeiros para a pesquisa nas áreas das Ciências Humanas e Sociais atualmente.

Contar uma história também a faz ser recriada, assim, a perspectiva histórica defendida aqui pressupõe que os diferentes registros e narrativas de psicólogos nos hospitais gerais não têm apenas o valor de fotografias estáticas, mas sim e, prioritariamente, têm o valor de propor uma nova compreensão que auxilie nas ações e representações atuais, construindo uma lógica prospectiva e não apenas retrospectiva.

Destacar nas instituições e nos indivíduos a história que os constrói ajuda no rompimento da lógica cartesiana tão impregnada em nossa formação acadêmica e em nosso diaa-dia, já que evidencia a rede não linear e quase infinita de relações, subjetividades, mecanismos de poder e paradigmas flutuantes. Como conclusão final, ressaltamos que a história não diz respeito a um viés eletivo, mas sim a um substrato que permeia toda a construção de uma determinada disciplina, tornando-se indispensável por mostrar que a História, assim como a Linguagem, só se corporifica a partir do momento em que é compartilhada e mergulhada em suas redes de significação social e cultural.

\section{Referências}

Angerami-Camon, V. A. (2002). Apresentação. In V. A. Angerami-Camon (Org.), Novos rumos na psicologia da saúde. São Paulo: Pioneira Thomson Learning.

Angerami-Camon, V. A. (2004). Psicologia hospitalar: Pioneirismo e as pioneiras. In V. A. Angerami-Camon (Org.), $O$ doente, a psicologia e o hospital (pp. 1-29). São Paulo: Pioneira Thomson Learning.

Brasil. Ministério da Saúde. (2002). Legislação em saúde mental 1990-2002 (3a ed.). Brasília, DF: Ministério da Saúde.

Doca, F. N. P., \& Costa Júnior, A. L. (2007). Preparação psicológica para admissão hospitalar de crianças: Uma breve revisão. Paidéia (Ribeirão Preto), 17, 167-179.

Fleck, L. (1979). Gênesis and development of a scientific fact. Chicago, IL: The University of Chicago Press. (Original publicado em 1935)

Fongaro, M. L. H., \& Sebastiani, R. W. (1996). Roteiro de avaliação psicológica aplicada ao hospital geral. In V. A. Angerami-Camon (Org.), E a psicologia entrou no hospital (pp. 5-64). São Paulo: Pioneira Thomson Learning.
Gioia-Martins, D., \& Rocha Júnior, A. (2001). Psicologia da saúde e o novo paradigma: Novo paradigma? Psicologia: Teoria e Prática, 3(1), 35-42.

Huffman, K., Vernoy, M., \& Vernoy, J. (2003). Psicologia. São Paulo: Atlas.

Impagliazzo, S. P., Santos, F. M. S., Santos, C. F., Silva, M. A., Gonçalvez, V. P. e cols. (2003). Projeto de atenção a situações de risco psicossocial da equipe de saúde mental do Hospital Estadual Rocha Faria. Manuscrito não-publicado, Hospital Estadual Rocha Faria, Rio de Janeiro, RJ.

Löwy, I. (1994). Fleck e a historiografia recente da pesquisa biomédica. In V. P. Carrero (Org.), Filosofia, história e sociologia das ciências I: Abordagens contemporâneas (pp. 233-250). Rio de Janeiro: FIOCRUZ.

Maslow, A. H. (s/d). Introdução à psicologia do ser. Rio de Janeiro: Eldorado.

Matarazzo, J. D. (1980). Behavioral health and behavioral medicine: Frontiers for a new health psychology. American Psychologist, 35, 807-817.

Myers, D. G. (1999). Introdução à psicologia geral. Rio de Janeiro: LTC.

Pereira, F. M. (2003). A inserção do psicólogo no hospital geral: A construção de uma nova especialidade. Dissertação de mestrado não-publicada, Fundação Oswaldo Cruz, Rio de Janeiro.

Pfuetzenreiter, M. R. (2002). A epistemologia de Ludwik Fleck como referencial para a pesquisa no ensino na área de saúde. Ciência e Educação, 8, 147-159.

Pitta, A (1999). Hospital: Dor e morte como oficio (3a ed.). São Paulo: Hucitec.

Spink, M. J. P. (2003). Psicologia social e saúde: Práticas, saberes e sentidos. Petrópolis, RJ: Vozes.

Straub, R. O. (2005). Psicologia da saúde. Porto Alegre: Artmed.

Yamamoto, O. H. (1990). A psicologia escolar em Natal: Características e perspectivas. Psicologia Ciência e Profissão, 10(2/4), 40-49.

Fabia Monica Souza dos Santos é Professora Auxiliar da Universidade Estácio de Sá, campus R9/Taquara.

Ana Maria Jacó-Vilela é Professora Titular da Universidade do Estado do Rio de Janeiro.
Recebido: 06/05/2008

$1^{a}$ revisão: $16 / 01 / 2009$

$2^{a}$ revisão: $18 / 02 / 2009$

Aceite final: 13/04/2009 